\title{
Estudio de las intercaras acero rápido-fundición nodular generadas en procesos de moldeo por doble colada centrifugada
}

\author{
I. FERNÁNDEZ, A. ZIADI, F. J. BELZUNCE \\ Escuela Politécnica Superior de Ingenieros de Gijón. Universidad de Oviedo. Campus de Viesques
}

\begin{abstract}
Se han estudiado las intercaras de cilindros de laminación compuestos, formados por un acero rápido como material de la capa, y una fundición nodular como material del núcleo, fabricados mediante el método de la doble colada centrifugada. Durante el proceso de fabricación, especialmente en el lento enfriamiento hasta su desmoldeo y durante el tratamiento térmico posterior, tienen lugar fenómenos de difusión del carbono del núcleo hacia la capa y de los elementos aleantes del acero, más aleado, hacia el núcleo, dando lugar a que se originen una serie de microestructuras muy duras y frágiles en la zona de unión de ambos metales, que pueden llegar a debilitar dicha unión. Se han preparado las muestras metalográficamente y se han estudiado con la ayuda de un microscopio óptico y un microscopio electrónico asociado a una microsonda. Se destaca como aspectos más significativos, la formación de una región fuertemente descarburada en la zona de la intercara próxima a la fundición, y a continuación de ésta, una región muy dura y frágil caracterizada por una importante acumulación de grandes carburos.
\end{abstract}

Palabras clave: cilindros de laminación, interfase, rodillos bimetálicos, colada centrifugada.

Study of the high strenght steel- nodular iron interphase developed in bimetallic rolls produced by centrifugal casting

The interphase of bimetallic rolling rolls produced by centrifugal casting using a high speed steel to make the shell and a ductile gray iron for the core was studied. During the manufacturing method and especilly in the course of the slow cooling before demoulding and also during the characteristic long heat treatments always necessary, diffusion phenomena of both, carbon from the core to the shell, and of the shell alloying elements in the oposite direction, take place, giving different micostructures which can reduce the strength of the interphase. A metallographic analisys, using optical and electronic microscopies, was performed and, as a result of it, a highly decarburized region in the vicinity of the core and a very hard and brittle adyacent zone with an important accumulation of different carbides are the most relevant microstructural results.

Keywords: rolling rolls, interphase, bimetallic rolls, centrifugal casting.

\section{INTRODUCCIÓN}

Antiguamente, los cilindros de laminación eran fabricados de un único material, principalmente fundiciones o aceros. Actualmente, con el fin de obtener mejores propiedades mecánicas (mayor dureza superficial y resistencia) y mayores periodos de vida de los cilindros de laminación, muchos de los cilindros utilizados son de tipo compuesto, constituidos por un material exterior, más aleado, que es el que soporta las mayores tensiones y esfuerzos, y otro interior al que simplemente se le exige una buena resistencia mecánica y tenacidad. Este tipo de cilindros con un material para la capa y otro distinto para el núcleo, se fabricó por primera vez en Alemania durante los años 60.(1)

\section{MATERIALES Y MÉTODO DE FABRICACIÓN}

El acero rápido, utilizado para la fabricación de la capa externa se caracteriza por la presencia de cantidades notables de elementos formadores de carburos (Mo, W, V, Cr, Nb). La composición química de los cilindros utilizados en este estudio con capa de acero rápido y núcleo de fundición nodular se recoge en la tabla I.

TABla I COMPOSICIÓN QUímICA DE LOS CILINDROS DE ACERO RÁPIDO-FUNDICIÓN NODULAR

\begin{tabular}{|l|c|c|c|c|c|c|c|c|c|}
\hline & $\% \mathbf{C}$ & $\% \mathbf{M N}$ & $\%$ SI & $\% \mathbf{C R}$ & $\% \mathbf{N I}$ & $\% \mathbf{M O}$ & $\% \mathbf{W}$ & $\% \mathbf{V}$ & $\% \mathbf{N B}$ \\
\hline Capa & $1,7-2,2$ & ---- & ---- & $5-8$ & ---- & $2-6$ & $2-6$ & $4-7$ & $0-5$ \\
\hline Núcleo & $2,7-3,5$ & 0,6 & $1-2$ & $0,1-0,6$ & $1,5-2,5$ & $0,1-0,5$ & ---- & ---- & ---- \\
\hline
\end{tabular}

Existen varias maneras de fabricar los cilindros de laminación compuestos. Desde su introducción a finales de los años 60, el método de la doble colada centrifugada sigue siendo el sistema de fabricación más competitivo en la producción de cilindros compuestos para los TBC (trenes de bandas en caliente),(2) y ha sido precisamente este método el utilizado para la obtención de los cilindros estudiados en este trabajo.

Este método consiste en colar en primer lugar el caldo del material que va a formar la tabla del cilindro en un molde rotativo y aprovechando la fuerza centrífuga, el material se adapta a las paredes del molde, solidificando en la forma deseada. Una vez solidificada la capa externa, se vierte un segundo caldo del material que va a formar el núcleo y los cuellos del cilindro y se deja solidificar ya estáticamente. Es necesario realizar un buen control de las condiciones del proceso en el momento de verter el segundo caldo, con el fin de lograr la fusión completa de la intercara capa-núcleo, evitando al mismo tiempo una mezcla excesiva de ambos productos, para asegurar la formación de una intercara sana y sin defectos.

\section{TÉCNICAS EXPERIMENTALES}

Los cilindros de laminación tras ser fabricados utilizando la técnica de moldeo centrifugado ya descrita, son sometidos a tratamientos térmicos posteriores con el fin de obtener la microestructura más apropiada para soportar sus solicitaciones del servicio. Los cilindros 
de acero rápido utilizados en este estudio, fueron sometidos a un tratamiento térmico que consistió en una austenización a $1100^{\circ} \mathrm{C}$ durante 20h, en un horno de laboratorio seguido de un enfriamiento al aire.

Las probetas en estado bruto de moldeo y tras tratamiento térmico se examinaron mediante microscopía óptica y electrónica de barrido. La composición química de los carburos presentes se determinó con la ayuda de una microsonda electrónica.

También se han realizado ensayos de dureza Vickers (bajo una carga de $31,25 \mathrm{~kg}$ ) en las zonas de las intercaras entre la capa y el núcleo.

\section{RESULTADOS}

\subsection{Perfiles de dureza}

La figura 1 muestra los perfiles dureza obtenidos en la zona de la intercara.

Tras el tratamiento térmico se aprecia un aumento de dureza en la zona de la fundición, justificado por la mayor formación de carburos en esta zona. La variación de la dureza de la capa se justifica en virtud de modificaciones en su constituyente matriz que implica el tratamiento de temple.

\subsection{Microestructura}

Durante el proceso de fabricación de los cilindros de laminación compuestos, especialmente en el lento enfriamiento del cilindro hasta su desmoldeo, y luego, durante los largos tratamientos térmicos posteriores, (especialmente en la austenización a alta temperatura previa al temple), necesarios para conferir a la tabla del cilindro las propiedades requeridas, tienen lugar fenómenos de difusión del carbono desde el núcleo hacia la capa y de los aleantes mayoritarios de la capa (Cr, Mo, $\mathrm{W}, \mathrm{V}$ y Nb) hacia la fundición gris, dando lugar a que se originen unas microestructuras diversas en la zona de la unión entre el material del núcleo y de la capa (3).

$\mathrm{Al}$ observar metalográficamente estas intercaras, se pueden destacar como hechos más significativos generales los siguientes(véase figura 2):

1. Aparición de una zona descarburada en la región de la intercara próxima a la fundición gris, que se justifica en virtud de la difusión del carbono hacia el material de la capa, amplificada por la

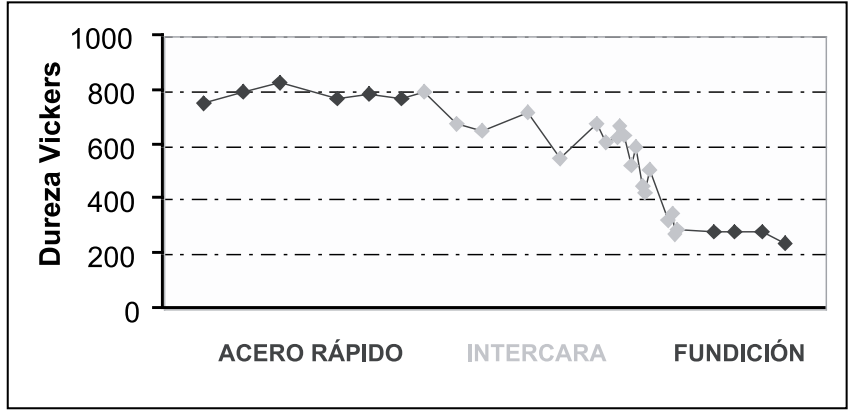

a) Acero rápido-fundición nodular en estado bruto de moldeo

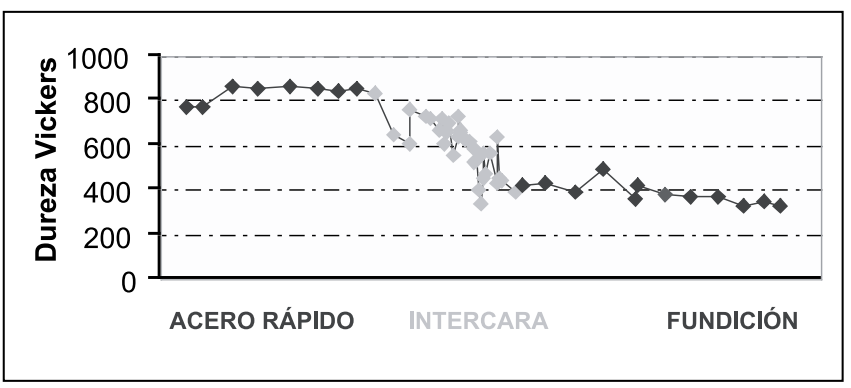

b) Acero rápido-fundición nodular después del tratamiento térmico

Figura 1. a)Acero rápido-fundición nodular en estado bruto de moldeo; b)Acero rápido-fundición nodular después del tratamiento térmico

especial atracción que ejerce sobre este elemento la importante presencia de elementos carburígenos en la capa del cilindro(4).

2. Por otro lado, en la región adyacente, por el lado del material de la capa, el carbono difundido de la manera explicada, se combina con los aleantes presentes y origina una importante acumulación de carburos que dan lugar a una región de grandes carburos muy dura y frágil.

Seguidamente se van a mostrar detalles concretos de las diferentes subzonas que caracterizan la intercara entre la capa y el núcleo de los cilindros.

La figura 3 muestra la zona correspondiente al núcleo, dónde, en virtud de la solidificación parcial de la capa, se han incorporado elementos carburígenos que han promovido la formación de carburos

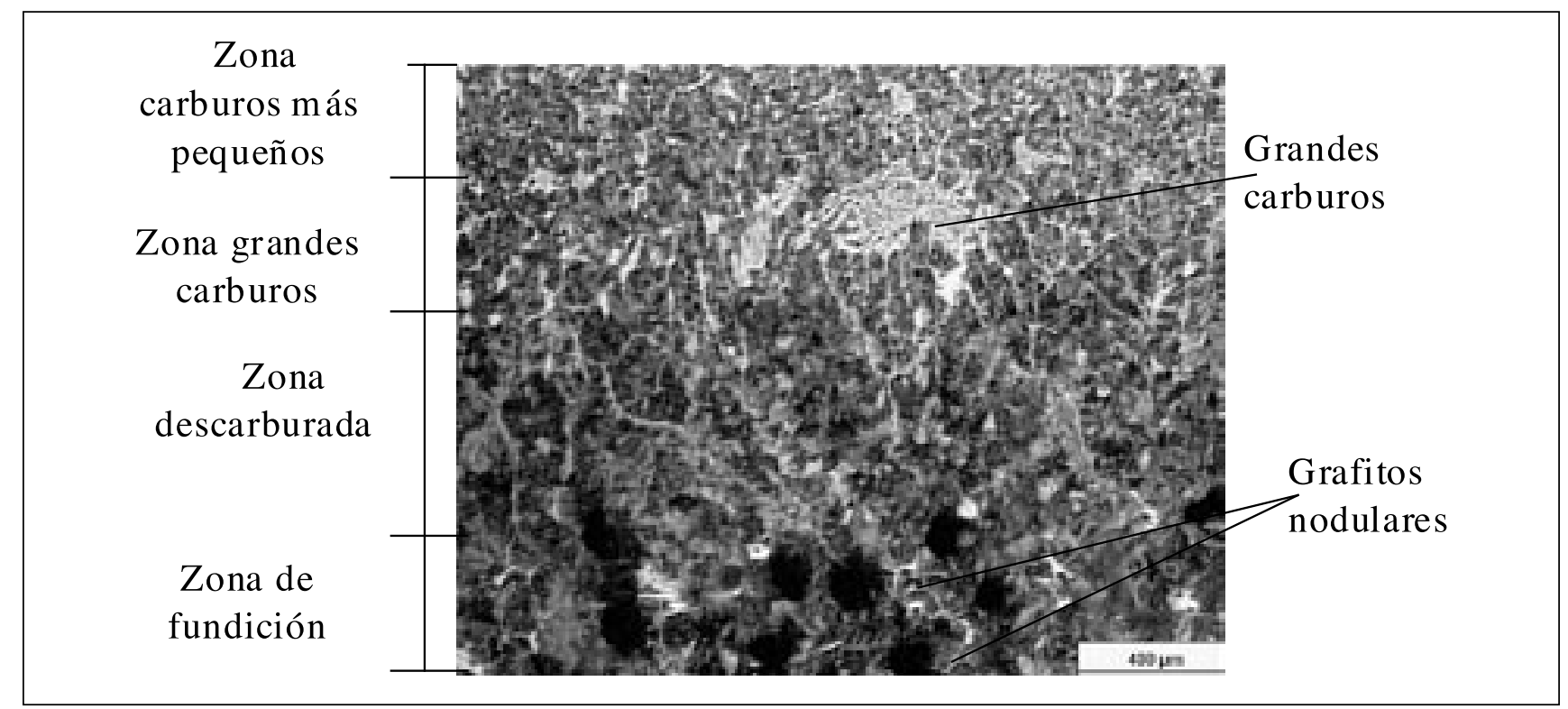

Figura 2. Intercara acero rápido-fundición nodular. Estado bruto de moldeo 
además de grafito. La figura 4 muestra el aspecto general de la región descarburada, en la que han desaparecido los nódulos de grafito de tal manera que consta de unos finos carburos intergranulares en una matriz perlítica. La figura 5 representa la zona inmediatamente adyacente en la que se manifiesta una importante proporción de carburos en una matriz perlítica. La tabla 2 da cuenta de la composición media de estos carburos que como se ve son carburos mixtos de hierro y cromo, aunque también se ha puesto de manifiesto la presencia de carburos de vanadio.

TABLA II. COMPOSICIÓN MEDIA DE LOS CARBUROS DE Cr-Fe Y DE LOS DE V (EN \% ATÓMICO)

\begin{tabular}{|l|c|c|c|c|c|c|}
\hline & C & FE & CR & V & MO & W \\
\hline Carburos de Cr-Fe & 34,19 & 45,2 & 13,56 & 4,36 & 1,29 & 0,1 \\
\hline Carburos de V & 47,44 & 2,29 & 4,82 & 39,61 & 3,06 & 3,06 \\
\hline
\end{tabular}

Al seguir avanzando hacia la capa, aparece una región en la que se observa un cambio en el constituyente matriz que deja de ser perlita para convertirse en una mezcla de austenita y martensita (se ha determinado mediante difracción de rayos X), similar al de la región de la tabla de acero rápido, no afectada por el proceso de fabricación que se muestra en la figura 6: el acero rápido constitutivo de la tabla consta de carburos de cromo de tipo eutéctico y carburos de vanadio más dispersos, en una matriz de martensita y austenita retenida.

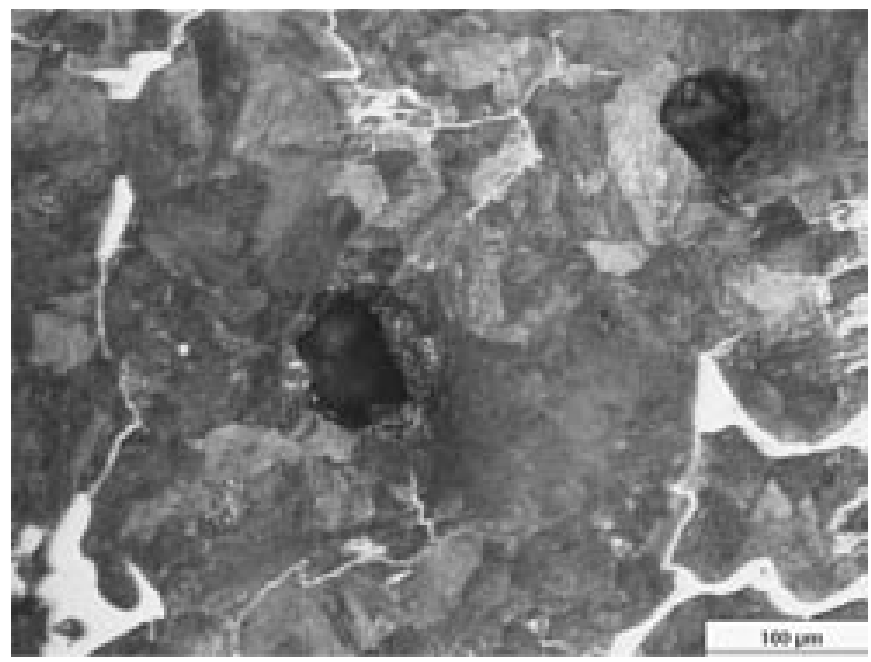

Figura 3. Región del núcleo: nódulos de grafito, matriz perlítica

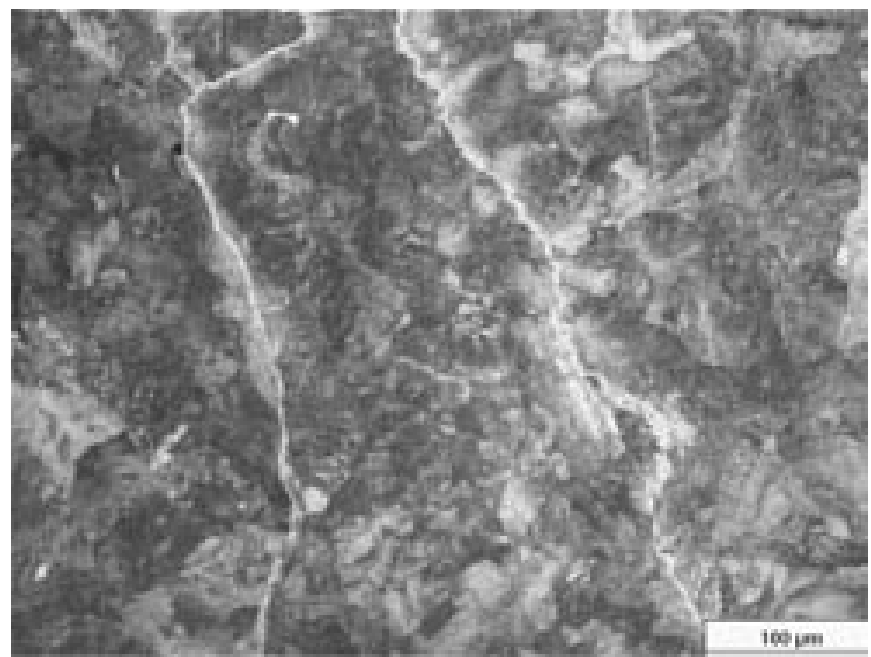

Figura 4. Región descarburada: perlita y cementita intergranular
Las principales diferencias que se observan después del tratamiento térmico de temple, motivadas por la difusión que opera a las altas temperaturas del tratamiento de austenización es el incremento de la proporción de carburos en el núcleo próximo a la intercara y la aparición de martensita en la región de grandes carburos (véase figura 7).

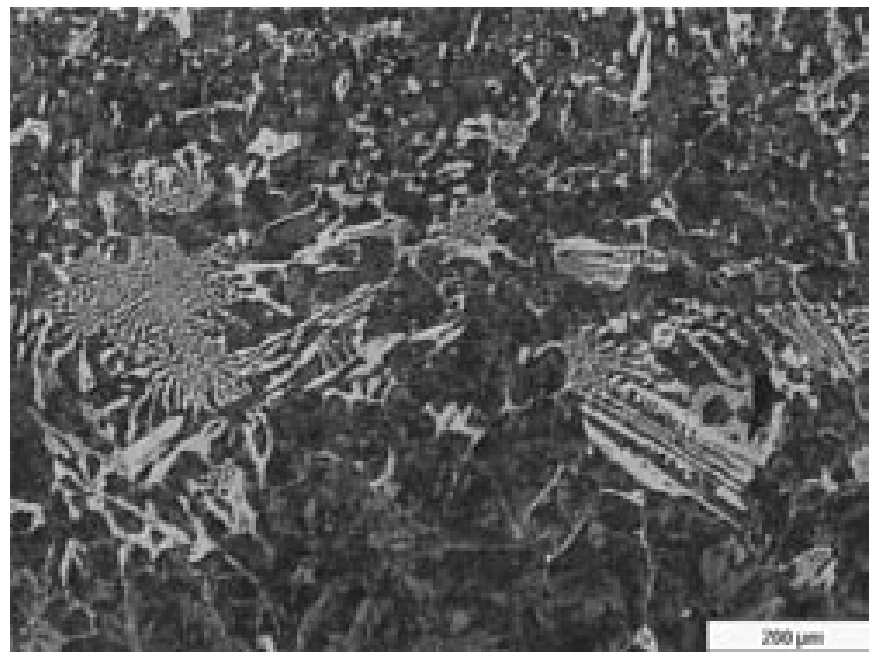

Figura 5.Región de acumulación de carburos

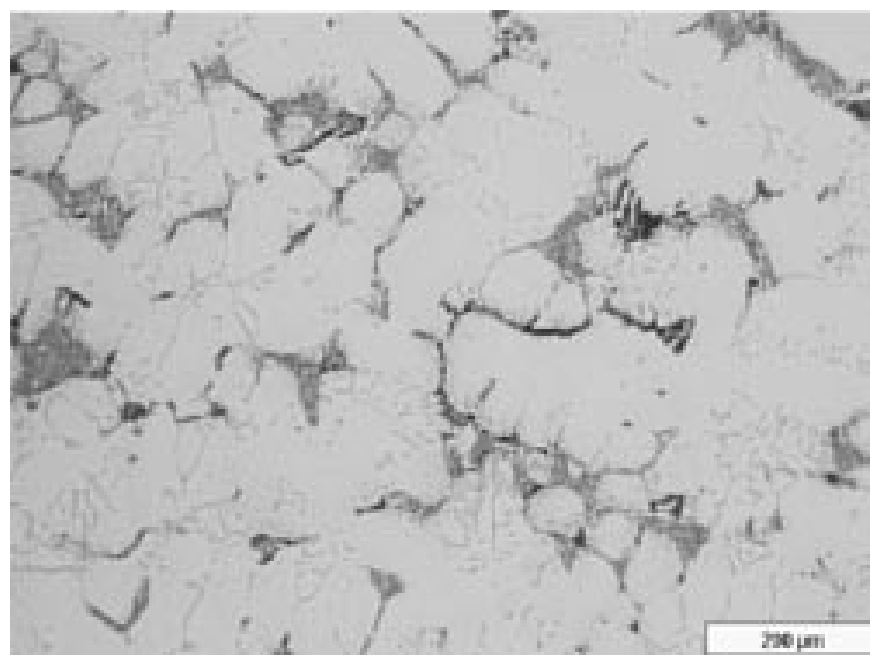

Figura 6. Región de la capa no afectada: acero rápido

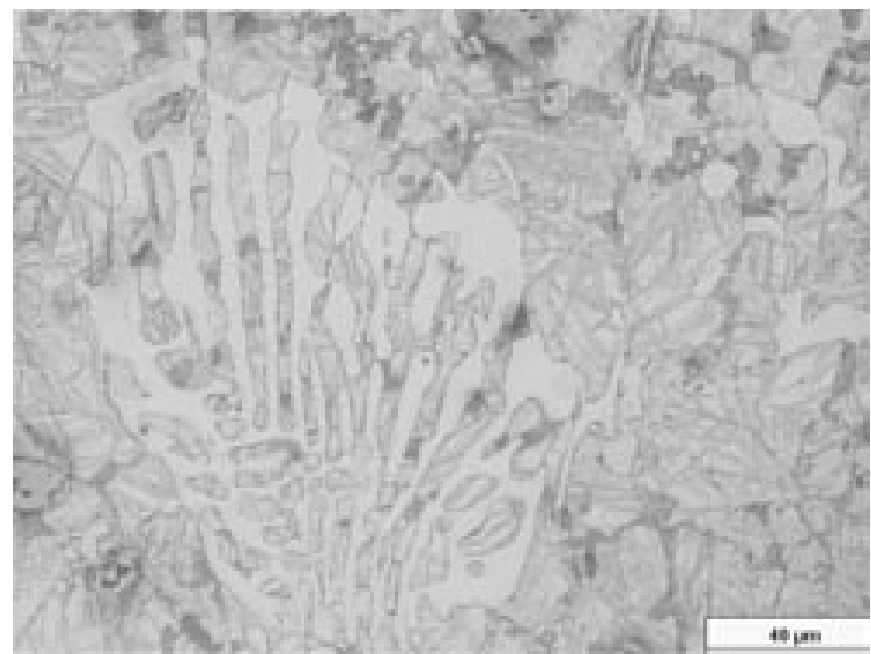

Figura 7. Zona de grandes carburos: matriz martensítica con algo de perlita Metalworking Industries. 


\section{CONCLUSIONES}

Se destacan las conclusiones siguientes:

- Formación de regiones típicas en la intercara, debidas a la difusión de elementos aleantes de la capa hacia el núcleo y del carbono del núcleo hacia la capa.

- Presencia de carburos en el núcleo que debería ser totalmente grafítico, debido a la fusión de un pequeño espesor de la capa al verter el caldo del núcleo. Esta presencia de carburos aumenta después de los tratamientos térmicos, y lo mismo ocurre con la dureza en esta región.

- La formación de la zona de grandes carburos que parece independiente del tratamiento térmico debe de intentar minimizarse por tratarse de una región dura y frágil pudiendo ser el origen de agrietamientos internos de los cilindros durante la fabricación o en el curso de su servicio.

- Las variaciones en el constituyente matriz (perlita o austenita y/o martensita) no son demasiado importantes porque, aunque sus propiedades son bien diferentes, éstas se uniformizan tras el imprescindible tratamiento térmico posterior al que son sometidos los cilindros.

\section{BIBLIOGRAFÍA}

1. P. Haper, "Manufacture of cast iron rolls", pp.87-111, en Rolls for the Metalworking Industries.

2. E. M. Lowe, "FEWTIC-Iron, tungsten and titanium carbide duplex rolls", International Center of Conference, Birmingan, Marzo 1996.

3. Hertzman S., Lille C., Frisk K., Blom R., Westman C., Petterson S. Nylén T.

"An experimental and theoretical study of the compositional and microstructural variations over de weld zone of compound HSS rolls", Swedish Institute for Metals Research, 2000

4. Lille C., Westman C., Hertzman S.

"Investigations of the compositional and microsturctural variatiosn over de bond zone of high seed steel compound rolls-Case study2, Swedish Institute for Metals Research, 2000

Recibido: 1.2 .03

Aceptado: 30.11 .03 